\title{
Comorbidities and its relation to performance status and estimated survival rate among cancer patients
}

\author{
Sankar VEINTRAMUTHU 1 (D), Rama PARTHASARATHY $2 *$ (D), Sangeetha MATHEW 2 (D), \\ Subash JOHN ${ }^{3}$ (D), Vignesh KANDA KUMAR ${ }^{3}$ (D), Prudence Attilade RODRIGUES ${ }^{2}$ (D) \\ 1 Department of Pharmaceutics, PSG College of Pharmacy, Affiliated to The Tamilnadu Dr.M.G.R.Medical \\ University, Coimbatore, Tamilnadu, India. \\ 2 Department of Pharmacy Practice, PSG College of Pharmacy, Affiliated to The Tamilnadu Dr.M.G.R.Medical \\ University Coimbatore, Tamilnadu, India. \\ 3 Department Oncology, PSG Hospitals, PSG Institute of Medical Sciences and Research, Coimbatore, Tamilnadu \\ India. \\ * Corresponding author. E-mail: ramapsg008@gmail.com (R.P.); Tel. +91-422-4345841.
}

Received: 10 June 2018 / Revised: 12 October 2018 / Accepted: 16 October 2018

\begin{abstract}
Many studies report the presence of comorbidities, which have a consequential impact on the management and survival of cancer patients. The aim of the present study is to assess the prevalence of comorbidities and their influence on overall management, estimated survival, and performance of cancer patients. A hospital based prospective study was conducted at a multi-specialty teaching hospital for a period of 10 months. Out of a sample of 140 cancer patients, 70 were diagnosed with comorbidities. Estimated survival rates and comorbidity scores were assessed using the Charlson Comorbidity Index (CCI). Performance scores were observed using the Eastern Cooperative Oncology Group (ECOG) performance score. CCI and performance score were statistically analyzed by SPSS Version 19. Hypertension (40\%) was the leading comorbidity, followed by diabetes (25.71\%). Those women with high $(>5)$ CCI score $(57.14 \%, p=0.04)$ had significantly decreased estimated survival rates of less than or equal to 2 months compared to those having less than $(<) 2 \mathrm{CCI}$ score and who reached estimated survival rates of more than or equal to 7 months. The performance score $(2.065 \pm 0.81)$ was significantly $(P=0.0001)$ increased after treatment of the comorbidity compared to the performance score $(1.125 \pm 1.27)$ of patients without comorbidity. Only alkylating agents (cyclophosphamide $p=0.003$, Carboplatin \& Oxaliplatin $p=0.007$, Cisplatin $p=0.0001$ ), and folic acid analogues (Leucovorin $\mathrm{p}=0.01$ ) showed significant differences in the management of cancer between groups. This study suggests that breast cancer is associated with increased comorbidity burden compared to other types of cancer. Also, comorbidity is associated with overall decreased estimated survival rate and performance status among cancer patients.
\end{abstract}

KEYWORDS: Cancer; comorbidity; estimated survival rate; treatment pattern; performance status; CCI; ECOG

\section{INTRODUCTION}

Every year, about 800,000 new cancer patients get registered with the National Cancer Registry Programme of India. Less than $30 \%$ of cancer patients in India survive for 5 years or longer after diagnosis. In the year 2010, cancer-related deaths in India was as high as 556,400[1]. This shows that cancer is one of the major health problems at present. While cancer is a big burden by itself, the effects of comorbidities are all the more overwhelming. Those conditions or diseases that have been present even before the diagnosis of cancer and which are not the side effects of cancer treatment are addressed as comorbidities [2]. Comorbidities have a direct and consequential impact on the management and, ultimately, the estimated survival rates of cancer patients [3]. Knowledge of the comorbidity can also help in enhancing quality of life by figuring out long term obstacles and mortality and thus changing and comparing medication options [4]. Most comorbidity studies do not contain information on the severity of the individual comorbid conditions, and clinical trials usually exclude patients with severe comorbid diseases. So, we lack information on the impact of severe comorbidities on cancer diagnosis, treatment, and outcomes [5].

The effect of comorbidities on estimated survival rates, performance status, and management of cancer in India is not scientifically reported in literature. The aim of this investigation is to assess the presence of

How to cite this article: Veintramuthu S, Parthasarathy R, Mathew S, John S, Kanda Kumar V, Rodrigues PA. Comorbidities and its relation to performance status and estimated survival rate among cancer patients. J Res Pharm. 2019; 23 (2): 304-314. 
comorbidities and their impact on performance status, estimated survival rates, and treatment patterns among cancer patients in a tertiary care hospital.

\section{RESULTS}

Out of the 140 patients who were recruited in our study, 139 completed the study and one discontinued due to death. Of these, 70 patients had at least one comorbidity and 69 patients did not have any comorbidity at all. During our study period, the selected sample consisted of $85(60.71 \%)$ females and 55(39.21\%) males. Based on their age, the respondents were grouped into 7 categories as depicted in (Table.1). The majority of patients $(n=51 ; 36.43 \%)$ fell in the age category of $66-75$ years. Altogether, $49 \%$ of the respondents were categorized under old age (between 60-90 years), while $43 \%$ were categorized under middle age (between 40 60 years), and only $9 \%$ were categorized below 40 years of age.

Table 1. Age and sex wise distribution of cancer patients.

\begin{tabular}{llll}
\hline Age group & $\begin{array}{l}\text { Total } \\
\mathbf{N}(\%)\end{array}$ & $\begin{array}{l}\text { Male } \\
\text { N (\%) }\end{array}$ & $\begin{array}{l}\text { Female } \\
\mathbf{N}(\%)\end{array}$ \\
\hline $26-35$ & $5(3.57)$ & $2(3.63)$ & $3(3.53)$ \\
$36-45$ & $15(10.71)$ & $6(10.91)$ & $9(10.58)$ \\
$46-55$ & $37(26.43)$ & $14(25.45)$ & $23(27.06)$ \\
$56-65$ & $28(20)$ & $11(20)$ & $17(20)$ \\
$66-75$ & $51(36.43)$ & $20(36.36)$ & $31(36.47)$ \\
$>76$ & $4(2.86)$ & $2(3.63)$ & $2(2.35)$ \\
Total & 140 & $55(39.29)$ & $85(60.71)$ \\
\hline
\end{tabular}

$\mathrm{N}$ - Number of patients.

Table 2 presents the observed numbers of cases during the study period based on the original site of the detected cancer. $37(26 \%)$ respondents were diagnosed with breast cancer, whereas the others had stomach $(12.86 \%)$, lung(10\%), colorectal(10\%), oesophageal(9.29\%), head \& neck(7.86\%), leukaemia(6.43\%), ovarian (5\%), cervical(4.29\%), pancreatic(2.14\%), endometrial(1.43\%), duodenal (1.43\%), prostate(1.43\%), and vaginal cancer $(1.43 \%)$. The family history and comorbidity of different types of cancer is shown in Table.2. $28.57 \%$ patients had a family history of cancer,, with the majority of them being ovarian cancer (57.14\%), followed by esophageal cancer (46.15\%). Information about family history was self-reported, and it is quite possible that some of subjects may not recall their family histories accurately. This study also had more female participants who statistically tend to show more family history of ovarian cancer. Among the 70 patients who had comorbidities, a majority $(40 \%)$ had hypertension. The next most common comorbidity $(26 \%)$ was diabetes mellitus. The least reported cases were of tuberculosis (2.8\%). Different comorbidities along with cancer are presented in (Fig.1). Within the comorbidity group, $68.57 \%$ had only one comorbidity, $22.86 \%$ had two comorbidities, and $8.57 \%$ had three types of comorbidities along with the cancer which is described in the (Fig.2).

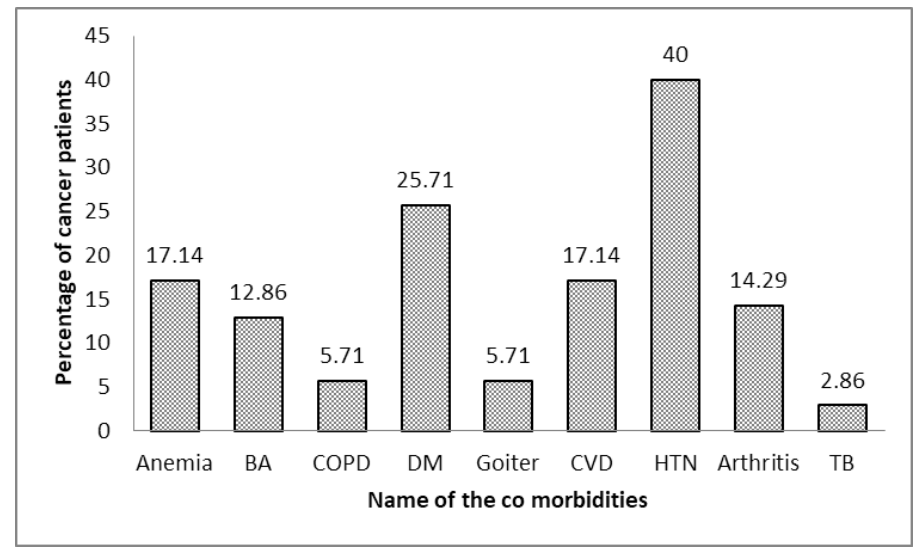

Figure 1. Comorbidities among cancer patients; BA-Brochial asthma, COPD - Chronic Obstructive Pulmonary Disease, DM - Diabetes Melitus, CVD - Cardiovascular diseases, HTN - Hypertension, TB - Tuberculosis. 
Table 2. Distribution of family history and comorbidity status of different type of cancer

\begin{tabular}{|c|c|c|c|c|c|}
\hline Type of cancer & $\begin{array}{l}\text { Total } \\
\text { N (\%) }\end{array}$ & $\begin{array}{c}\text { Presence of } \\
\text { Family History. } \\
\text { N (\%) }\end{array}$ & P value & $\begin{array}{c}\text { Presence of } \\
\text { Comorbidity. } \\
\mathrm{N}(\%)\end{array}$ & P value \\
\hline Breast & $37(26.43)$ & $11(29.73)$ & $0.0005^{*}$ & $26(70.27)$ & $0.0005^{*}$ \\
\hline Stomach & $18(12.86)$ & $8(44.44)$ & 0.5 & $11(61.11)$ & 0.18 \\
\hline Colorectal & $14(10)$ & - & - & $10(71.43)$ & $0.02^{*}$ \\
\hline Lung & $14(10)$ & $5(35.71)$ & 0.13 & $9(64.29)$ & 0.13 \\
\hline Oesophageal & $13(9.29)$ & $6(46.15)$ & 0.7 & $2(15.38)$ & $0.0005^{*}$ \\
\hline Head and neck & $11(7.86)$ & $5(45.45)$ & 0.67 & $4(36.36)$ & 0.2 \\
\hline Leukaemia & $9(6.43)$ & - & - & $2(22.22)$ & $0.02^{*}$ \\
\hline Ovarian & $7(5)$ & $4(57.14)$ & 0.6 & $5(71.42)$ & 0.12 \\
\hline Cervical & $6(4.29)$ & - & - & - & - \\
\hline Pancreatic & $3(2.14)$ & $1(33.33)$ & 0.45 & $2(66.67)$ & 0.45 \\
\hline Duodenal & $2(1.43)$ & - & - & - & - \\
\hline Endometrial & $2(1.43)$ & - & - & - & - \\
\hline Prostate & $2(1.43)$ & & - & - & - \\
\hline Vaginal & $2(1.43)$ & & - & - & - \\
\hline Total & $140(100)$ & $40(28.57)$ & $0.0001^{*}$ & $70(50)$ & 1 \\
\hline
\end{tabular}

$\mathrm{N}$ - Number of patients.

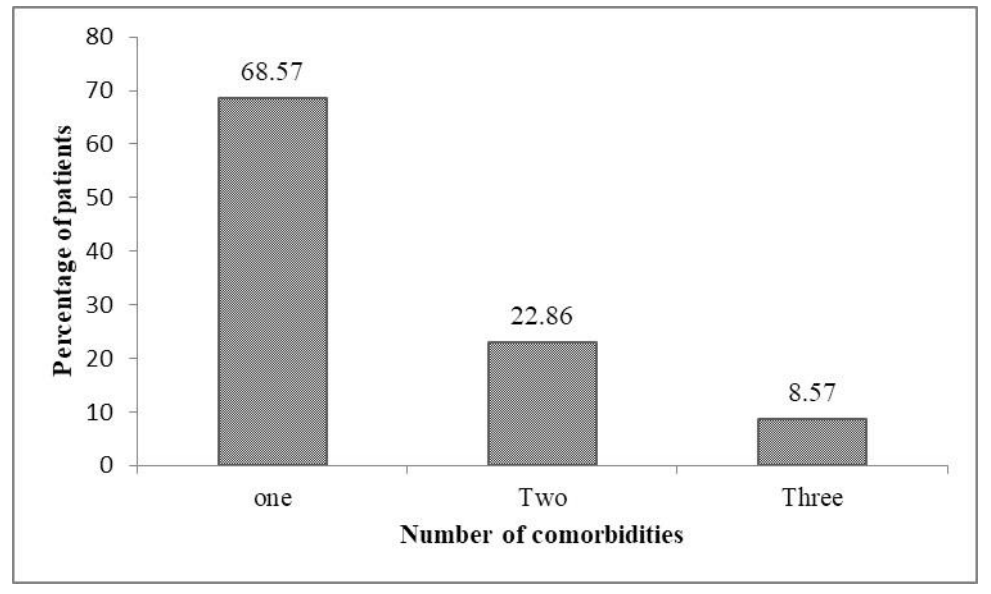

Figure 2. Number of Comorbidities among cancer patients.

Table 3 shows mean age, mean CCI score, and mean estimated survival rates for cancer patients with and without comorbidity. The estimated survival rate was calculated from the CCI scores. The patients with lower CCI scores (3) would have an estimated survival probability higher (7 months) than those with high CCI score $(6+2.48)$. Consequently, it was clear that patients without any comorbidity had higher estimated survival rates than patients with at least one comorbidity. However, this difference was not statistically significant.

In this study, breast cancer $(26.42 \%)$ was found to be the most prevalent type among the 140 cancer patients who had the highest $(70.27 \%)$ comorbidity with a mean age $54 \pm 6.71$. The mean age for those without comorbidity was $46 \pm 13.24(p=0.42)$. The estimated survival rate of patients without comorbidity was found to be 7 months and those with comorbidity was 4 months $(p=0.59)$.

The next point to be addressed is that the maximum numbers of patients were stomach cancer patients of which, 11(57.89\%) had at least one comorbidity with a mean CCI score of 5 and estimated survival of 2 years +2.87. Among the 15 lung cancer patients, 9 of them had at least one comorbidity. The mean age of patients with comorbidity was found to be $72 \pm 13.63$ and for those without comorbidity was $56 \pm 2.76$ ( $p=0.15)$. Patients without a comorbidity had estimated survival probability higher than those with at least one comorbidity $(\mathrm{p}=0.21)$. 
Table 3. Mean age, Mean CCI score and Mean Estimated Survival Rate of all cancer patients with and without comorbidity.

\begin{tabular}{lllllccccc}
\hline $\begin{array}{l}\text { Type of } \\
\text { cancer }\end{array}$ & $\begin{array}{c}\text { Comorbi- } \\
\text { dity }\end{array}$ & $\begin{array}{l}\text { Non- } \\
\text { comorbidity }\end{array}$ & $\begin{array}{c}\text { P } \\
\text { value }\end{array}$ & $\begin{array}{c}\text { Comorbi- } \\
\text { dity }\end{array}$ & $\begin{array}{c}\text { Non- } \\
\text { comorbidity }\end{array}$ & $\begin{array}{c}\text { P } \\
\text { value }\end{array}$ & $\begin{array}{c}\text { Comorbi- } \\
\text { dity }\end{array}$ & $\begin{array}{c}\text { Non- } \\
\text { comorbidity }\end{array}$ & $\begin{array}{c}\mathrm{P} \\
\text { value }\end{array}$ \\
\hline Breast & $54 \pm 6.71$ & $46 \pm 6.71$ & 0.42 & $4 \pm 1.06$ & 3 & 0.08 & $4 \pm 1.85$ & $7 \pm 2.21$ & 0.59 \\
Stomach & $63 \pm 9.93$ & $62 \pm 1.73$ & 0.92 & $5 \pm 0.94$ & 5 & 0.05 & $2 \pm 1.24$ & $2 \pm 0.94$ & 0.15 \\
Colorectal & $66 \pm 9.03$ & $69 \pm 4.09$ & 0.79 & $6 \pm 1.02$ & 5 & $0.02^{*}$ & $1 \pm 2.19$ & $2 \pm 1.2$ & 0.71 \\
Lung & $70 \pm 13.63$ & $56 \pm 2.76$ & 0.15 & $6 \pm 2.48$ & 4 & $0.02^{*}$ & $2 \pm 2.74$ & $5 \pm 0.74$ & 0.21 \\
Oesophageal & $63 \pm 2.5$ & $58 \pm 5.46$ & 0.65 & $5 \pm 0$ & 4 & $0.02^{*}$ & $2 \pm 0$ & $5 \pm 0.86$ & 0.09 \\
$\begin{array}{l}\text { Head and } \\
\text { neck }\end{array}$ & $66 \pm 4.06$ & $64 \pm 10.28$ & 0.86 & $6 \pm 0.5$ & 5 & 0.08 & $1 \pm 2.12$ & $2 \pm 2.87$ & 0.74 \\
Ovarian & $56 \pm 8.08$ & $42 \pm 4.71$ & 0.16 & $5 \pm 0$ & 3 & 0.05 & $2 \pm 1.6$ & $7 \pm 0$ & 0.28 \\
Pancreatic & $48 \pm 1.5$ & $55+1$ & 0.49 & $3 \pm 0$ & 4 & 0.08 & $7 \pm 0$ & $5 \pm 0$ & 1 \\
\hline
\end{tabular}

*statistically significant $\mathrm{p}$ value $<0.05$, other cancers did not have significant comorbidities.

Fifteen colorectal cancer patients were selected out of which 10 of them had at least one comorbidity. The estimated survival rate of patients without comorbidity was found to be 2 months and those with comorbidity was 1 month. Of the 8 ovarian cancer patients, 5 had at least one comorbidity, while the remaining 3 had just cancer alone. The most common comorbidity was hypertension, followed by diabetes. Twelve head and neck cancer patients were selected among which 4 of them had comorbidity while the rest 8 had cancer alone. The mean CCI score was 6 and for those without comorbidity was 5 ( $p=0.705)$. Our study sample included only 3 pancreatic cancer patients out of which 2 had comorbidities while 1 had cancer alone.

Our study population included 14 oesophageal cancer patients among which 2 of them had comorbidities while the rest 12 had cancer alone. The estimated survival rate of patients without comorbidity was found to be 7 months and those with comorbidities was 2 months, which is proof that patients without comorbidity have estimated survival probability higher than those with comorbidities $(p=0.09)$. Also, the performance score of patients with comorbidities was found to be higher than those without comorbidities $(\mathrm{p}=0.56)$. COPD was the main comorbidity present among oesophageal cancer patients.

Only 2 leukaemia patients were present in our study period and both of them had arthritis as comorbidity. The mean CCI score was 3 months and estimated survival rate of these patients was 7 months. The other cancer cases which did not have comorbidities were cervical, duodenal, endometrial, prostate, and vaginal cancers. The number of patients in each of these categories was 2 except for cervical (7). The estimated survival rate of all these patients was more than 7 months, except prostate and vaginal cancers. Their estimated survival rate was only 2 months as the patients were 70 years and above.

On comparing the CCI scores of patients, it was clearly found that patients without comorbidity had lesser score than patients with comorbidity. But, this difference was statistically significant for lung $(\mathrm{p}=0.02)$, colorectal $(p=0.02)$, and oesophageal cancer $(p=0.02)$. In terms of estimated survival rates, patients without comorbidity had a mean estimated survival rate of 7 months and for those with 1 comorbid condition had survival rate of 6 months; with 2 comorbidities hada survival rate of 4 months, and those with 3 comorbidities had a survival rate of 5 months.

Table 4 depicts the overall CCI score, estimated survival rate, and performance score of cancer patients. In the comorbidity group, $57.14 \%$ of women had a CCI score $>5$ compared to the group without comorbidity. $44.92 \%$ had a CCI score of $>5$ with P value of 0.28 . These women with high CCI score $(57.14 \%, \mathrm{p}=0.04)$ had significantly decreased estimated survival rate of less than or equal to 2 months compared to those with lesser CCI scores and with estimated survival rates of more than or equal to 7 months. 
Table 4. Comparison of CCI score, Estimated Survival Rate, ECOG performance scores of cancer patients.

\begin{tabular}{lccc} 
Parameters & $\begin{array}{c}\text { Comorbidity } \\
\mathbf{N}(\mathbf{\%})\end{array}$ & $\begin{array}{c}\text { Non-comorbidity } \\
\mathbf{N}(\%)\end{array}$ & P Value \\
\hline $\begin{array}{l}\text { CCI Score } \\
\leq 2\end{array}$ & $3(4)$ & $8(11.59)$ & 0.13 \\
3 & $11(15.71)$ & $15(21.73)$ & 0.43 \\
4 & $16(22.85)$ & $15(21.73)$ & 0.85 \\
$\geq 5$ & $40(57.14)$ & $31(44.92)$ & 0.28 \\
Estimated Survival Rate in months & & & \\
$\leq 2$ & $40(57.14)$ & $24(34.78)$ & $0.04^{*}$ \\
5 & $16(22.86)$ & $23(33.33)$ & 0.26 \\
$\geq 7$ & $14(20)$ & $22(31.88)$ & \\
Performance status & & & 0.12 \\
(Mean \pm SD) & & & $0.0001^{*}$ \\
Before treatment & $1.875 \pm 0.78$ & $1.625 \pm 1.11$ & $1.125 \pm 1.27$ \\
After treatment & $2.065 \pm 0.81$ & & \\
\hline
\end{tabular}

$\mathrm{N}$ - No of patients, *statistically significant $\mathrm{p}$ value $<0.05$.

The ECOG performance status of patients with and without comorbidity was observed and described in (Table 5). Higher the performance score, less active was the patient. In this survey, it was found that for patients with comorbidity, the performance score $(2.065 \pm 0.81)$ significantly $(\mathrm{P}=0.0001)$ increased after treatment compared to the performance score $(1.125 \pm 1.27)$ of patients without comorbidity. This could be due to the effects of both anticancer and comorbid drugs. Thus, it can be possibly stated that cancer patients without comorbidity show better performance than those with comorbidity.

Table 5. ECOG performance score of cancer patients.

\begin{tabular}{|c|c|c|c|c|c|c|}
\hline \multirow[b]{2}{*}{ Type of cancer } & \multicolumn{3}{|c|}{ Comorbidity } & \multicolumn{3}{|c|}{ Non-comorbidity } \\
\hline & $\begin{array}{c}\text { Before } \\
\text { treatment }\end{array}$ & $\begin{array}{c}\text { After } \\
\text { treatment }\end{array}$ & $\begin{array}{c}\mathbf{P} \\
\text { value }\end{array}$ & $\begin{array}{c}\text { Before } \\
\text { treatment }\end{array}$ & $\begin{array}{c}\text { After } \\
\text { treatment }\end{array}$ & $\begin{array}{c}\mathbf{P} \\
\text { Value }\end{array}$ \\
\hline Breast & $2 \pm 0.94$ & $2 \pm 1.15$ & 1 & $1 \pm 1.21$ & $0 \pm 1.23$ & $0.0001^{*}$ \\
\hline Stomach & $2 \pm 0.47$ & $2 \pm 0.94$ & 1 & $3 \pm 0.31$ & $3 \pm 0.48$ & 1 \\
\hline Colorectal & $2 \pm 1.01$ & $3 \pm 0.8$ & 1 & $1 \pm 0.48$ & $0 \pm 0.4$ & $0.0001^{*}$ \\
\hline Lung & $3 \pm 0$ & $4 \pm 0.86$ & $0.0001^{*}$ & $3 \pm 1.10$ & $3 \pm 1.06$ & 1 \\
\hline Oesophageal & $3 \pm 1.07$ & $2 \pm 0.78$ & $0.0001^{*}$ & $3 \pm 0.48$ & $2 \pm 0.4$ & $0.0001^{*}$ \\
\hline Head and neck & $1 \pm 0.5$ & $1 \pm 0.5$ & 1 & $1 \pm 0.43$ & $0 \pm 0.48$ & $0.0001^{*}$ \\
\hline Ovarian & $1.5 \pm 0.8$ & $2 \pm 1.32$ & $0.007^{*}$ & $0 \pm 0$ & $0 \pm 0.47$ & 1 \\
\hline Pancreatic & $1 \pm 0.5$ & $1 \pm 0.5$ & 1 & $1 \pm 0$ & $1 \pm 0$ & 1 \\
\hline
\end{tabular}

Distribution of anticancer drugs among comorbidity and non-comorbidity patients is described in Table 6. Overall, eighteen therapeutic regimens were prescribed among which $22 \%$ were single drug chemotherapy. $66 \%$ of these regimens were a combination of two drugs and $12 \%$ were triple drug combinations. In our population, the most frequently utilized antineoplastic agents were 5FU (26.43\%), lecovorin (20.71\%), and paclitaxel \&doxetaxel (18.57\%). Among these, leucovorin was mainly prescribed for the management of stomach (11patients) and colorectal cancer (9patients) within the comorbid group. This was not prescribed commonly with breast cancer patients.

Management of different types of cancer among comorbidity patients and non-comorbidity patients (Table 7) shows that Paclitaxel and Doxetaxel were given for 26 patients of whom 18 had comorbid conditions along with cancer. Regarding patients receiving antibiotic class of antineoplastic agents, Doxorubicin (17.85\%) was repeatedly advised for breast cancer with comorbidity group (25.71\%) compared to the non-comorbidity group $(0.1 \%) .26 .43 \%$ of patients receiving $5 \mathrm{FU}$ were in the category of stomach, colorectal, and lung cancer among the comorbidity group. 
Table 6. Distribution of anticancer drugs among comorbidity and non-comorbidity patients.

\begin{tabular}{|c|c|c|c|c|}
\hline Antineoplastic agents & $\begin{array}{r}\text { Total } \\
\text { N (\%) } \\
\end{array}$ & $\begin{array}{c}\text { Comorbidity } \\
\text { N (\%) }\end{array}$ & $\begin{array}{c}\text { Non Comorbidity } \\
\text { N }(\%)\end{array}$ & P Value \\
\hline Doxorubicin/Epirubicin & $29(20.71)$ & $18(25.71)$ & $11(15.71)$ & 0.14 \\
\hline Cyclophosphamide & $23(16.42)$ & $18(25.71)$ & $5(7.14)$ & $0.003^{*}$ \\
\hline Paclitaxel/Docetaxel & $34(24.28)$ & $21(30)$ & $13(18.57)$ & 0.1 \\
\hline 5-Flurouracil & $60(42.85)$ & $26(37.14)$ & $34(48.57)$ & 0.17 \\
\hline Carboplatin/Oxaliplatin & $24(17.14)$ & $18(25.71)$ & $6(8.57)$ & $0.007^{*}$ \\
\hline Cisplatin & $35(25)$ & $4(5.71)$ & $31(42.28)$ & $0.0001^{*}$ \\
\hline Leucovorin & $30(21.42)$ & $21(30)$ & $9(12.85)$ & $0.01^{*}$ \\
\hline Etoposide & $3(2.14)$ & $1(1.42)$ & $2(2.85)$ & 0.55 \\
\hline Imatinib & $2(1.42)$ & $2(2.85)$ & - & - \\
\hline
\end{tabular}

Table 7. Management different type of cancer among with comorbidity and non-comorbidity patients.

\begin{tabular}{|c|c|c|c|c|}
\hline Type Of Cancer & Treatment Regimen & $\begin{array}{c}\text { Comorbidity } \\
\text { N (\%) }\end{array}$ & $\begin{array}{c}\text { Non Comorbidity } \\
\text { N }(\%)\end{array}$ & P Value \\
\hline \multirow[t]{5}{*}{ Breast Cancer } & $\mathrm{AC}$ & $16(61.54)$ & $3(27.27)$ & \multirow{5}{*}{0.4} \\
\hline & Paclitaxel & $10(38.46)$ & $3(27.27)$ & \\
\hline & $\mathrm{A}+5 \mathrm{FU}$ & 0 & $2(18.18)$ & \\
\hline & $5 \mathrm{FU}+\mathrm{A}+\mathrm{C}$ & 0 & $2(18.18)$ & \\
\hline & Carboplatin & 0 & $1(9.09)$ & \\
\hline \multirow[t]{4}{*}{ Stomach Cancer } & $\mathrm{LV}+5 \mathrm{FU}$ & $8(72.72)$ & $1(14.28)$ & \multirow{4}{*}{0.5} \\
\hline & Cisplain $+5 \mathrm{FU}$ & $1(9.09)$ & $2(28.57)$ & \\
\hline & Docetaxel & $2(18.18)$ & 0 & \\
\hline & Cisplain+Epirubicin & 0 & $4(57.14)$ & \\
\hline \multirow[t]{3}{*}{ Colorectal Cancer } & Oxaliplatin+LV+5FU & $5(50)$ & $1(25)$ & \multirow{3}{*}{1} \\
\hline & $\mathrm{LV}+5 \mathrm{FU}$ & $5(50)$ & $1(25)$ & \\
\hline & Cisplatin+5FU & 0 & $2(50)$ & \\
\hline \multirow[t]{3}{*}{ Lung Cancer } & Paclitaxel +Carboplatin & $6(66.66)$ & $1(20)$ & \multirow{3}{*}{0.14} \\
\hline & $\mathrm{LV}+\mathrm{FU}$ & $2(22.22)$ & $2(40)$ & \\
\hline & Cisplain+Etoposide & 1(11.11) & $2(40)$ & \\
\hline \multirow[t]{4}{*}{ Esophageal Cancer } & $\mathrm{AC}$ & $2(100)$ & 0 & \multirow{4}{*}{1} \\
\hline & Cisplatin+FU & 0 & $3(27.27)$ & \\
\hline & Cisplatin +Docetaxel & 0 & $4(36.36)$ & \\
\hline & Cisplain+LV & 0 & $4(36.36)$ & \\
\hline \multirow[t]{2}{*}{ Pancreatic cancer } & LV+5FU & $1(25)$ & 0 & \multirow[t]{2}{*}{0.16} \\
\hline & Cisplatin $+5 \mathrm{FU}$ & 0 & $2(75)$ & \\
\hline \multirow[t]{3}{*}{ Head \& Neck } & Carboplatin $+5 \mathrm{FU}$ & $2(16.66)$ & 0 & \multirow[t]{3}{*}{0.24} \\
\hline & Cisplatin+5FU & $2(16.66)$ & $6(50)$ & \\
\hline & Cisplatin+ Docetaxel & 0 & $2((16.66)$ & \\
\hline \multirow[t]{2}{*}{ Ovarian } & Paclitaxel+ Carboplatin & $3(37.5)$ & $3(37.5)$ & \multirow[t]{2}{*}{0.23} \\
\hline & Carboplatin & $2(25)$ & 0 & \\
\hline
\end{tabular}

N - No of patients, A- Adriamycin, C - cyclophosphamide, 5FU -5 Flurouracil, LV- Leucovorin, *statistically significant $\mathrm{p}$ value $<0.05$.

The majority of the patients getting alkylating agents (Cyclophosphamide 25.71\%, Carboplatin \&Oxaliplatin $15.71 \%$, Cisplatin $4.28 \%$ ) were in the comorbid group as therapy for esophageal and breast cancer. In the non-comorbidity group, the more widely used chemotherapeutic was Cisplatin (30\%), which is given in combination with other antineoplastic drugs like Leucovorin, 5FU, Epirubicin, and Doxetaxel. Only alkylating agents (cyclophosphamide $\mathrm{p}=0.003$, Carboplatin \&Oxaliplatin $\mathrm{p}=0.007$, Cisplatin $\mathrm{p}=0.0001$ and folic acid analogues (Leucovorin $\mathrm{p}=0.01$ ) class of drugs showed significant differences in the management of cancer between co-morbidity and non-comorbidity groups, but others did not show significant differences in this regard. 


\section{DISCUSSION}

We evaluated the various comorbidities; performance status, and subsequently the treatment patterns among cancer patients.

During the study period, breast cancer was found to be more prevalent, followed by stomach and lung cancer. Therefore, the overall incidence rate among females was higher when compared to males. This study also suggests that the elders among males and females have more incidence of cancer. According to an earlier study in India, the leading causes of death in the age group of $30-70$ years was breast cancer, stomach cancer, and lung cancer. A study conducted by Mohandas KM et al indicates that breast cancer was the most frequently diagnosed cancer, accounting for more than one in five of all deaths from cancer in women[6].

The incidence is more above the age of 40 years, contributing to nearly $90 \%$ of the cancer patients reported. The lowest age reported in this study was less than 30 years. Gopalakrishnan $S$ et al. reviews that the occurrence of cancer is increased above the age of 40 years and the data from the registry shows that as age advances the incidence of cancer also increases[7]. As per the NCI statement, advancing age is the progressing key factor for many individual cancer types because of changes in the gene material [8].

From epidemiological studies, it is clear that $70-90 \%$ of the reasons of increasing cancer are connected to environment and to the standard of living of a person. Accordingly, cancer is preventable to a great extent. Heredity also plays a minor role in causing cancer, which accounts for just five percentage of cancer cases, while the rest is caused by non-heredity factors such as lifestyle and physical activity.

In our study population, breast cancer was found to be in higher frequency in the comorbidity age group of 50 - 60 years. Results from our study demonstrated that in patients aged 0-50 years, comorbidity is relatively rare and the predominant cause of death is breast cancer, probably owing to a more unfavorable prognostic profile. This is true with previous studies that have confirmed that presence of comorbidity during breast cancer diagnosis increases the risk of dying from breast cancer. Breast cancer cases suffered marginally more from DM, which is a known factor for the development of cancer. This is proved by meta-analysis that showed significant increased risk of breast cancer among women with diabetes. Tuberculosis had the lowest prevalence among the study participants $[9,10]$.

The Mean CCI score of stomach cancer was equal for patients with and without comorbidity because of the resemblance in the mean age (63 \pm 9.93$)$ of the two groups. Sarfarti et.al studies observed that stomach cancer patients with high comorbidity were likely to show high mortality than those without comorbidity and substantially less likely to receive curative therapy [11]. Prostate cancer was not reported in this study.

The result of another study coincides with our results, which concluded that lung cancer is frequently present with other diseases, like chronic obstructive lung disease, cerebrovascular diseases, heart failure, and myocardial infarction [12]. Such types of comorbidities may by themselves have a negative effect on estimated survival by delaying the diagnosis and advancing the stage of lung cancer. The most severe comorbidity, which worsened performance status, was a combination of COPD and hypertension among lung cancer patients.

Colorectal cancer had significantly more comorbidities, which was osteoporosis and combination of diabetes and ischemic heart disease. This reduces the performance score of the patients and these results correlate with the results of other reports [13]. Studies confirm that colorectal cancer is mostly caused by lifestyle factors such as less healthy diet, obesity, and poor physical activity as well as conditions like DM and vascular diseases[14].

An association between hypertension or alternatively hypertensive drugs and cancer, including ovarian cancer, has previously been studied [15]. In addition, diabetes mellitus has been suggested as a risk factor for ovarian cancer as well as other cancers by earlier research reports [16]. But in this study, none of the above associations could be found as the patients had these comorbidities even before the study was initiated. Mortality was higher among patients with comorbidities. Also, the performance score worsened for patients who had hypertension [17].

The comorbidities present among pancreatic cancer patients was diabetes mellitus and hypertension. A previous study outcome concluded that the bilateral causality between pancreatic cancer and diabetes has been widely documented. Type 2 diabetes could be either a cause, and/or possibly a consequence of pancreatic cancer. Also, hypertension is more common in patients with diabetes than those without. Epidemiological studies have confirmed a higher incidence of diabetes in pancreatic cancer, as well as a higher incidence of pancreatic cancer in diabetic patients [18]. These associations provide evidence-based medical support for further studies examining the mechanism of interaction. 
In this study, patients with two comorbidities survived less than those with three comorbidities, which is contrary to studies that concluded that the greater the number of co-morbid conditions is associated with declining overall general health and quality of life [19]. This could be that the comorbidities were severe and moreover, age is the most predominant factor to calculate the CCI score. Almost $68 \%$ of the patients with comorbidity were above 50 years of age. For each increasing age, the CCI score also increases and this directly reduces the estimated survival rate. Earlier reports have said that the presence of comorbid conditions have a negative effect on estimated survival and the patient's age alone does not have a major influence on estimated survival rate [20].

After the diagnosis, all the patients were considered for mastectomy with or without neoadjuvant chemotherapy based on the size of the tumor. The combination of radiotherapy and chemotherapy was the most common treatment procedure followed by surgery. In these cases, a comorbidity condition doesn't affect the mode of treatment of cancer. However, there will still be a need to consider the presence of comorbidity to improve the quality of life during the survival period.

Among the chemotherapeutic agents, 5- Fluorouracil was prescribed for all kinds of cancer irrespective of the presence of comorbidity conditions. It is an antimetabolite fluoro pyrimidine analogue of nucleoside pyrimidine with antineoplastic activity. Leucoverin was used for most of the patients with comorbidity, whereas, cisplatin was mostly used for patients without comorbidity. Patients diagnosed with colorectal cancer were mostly treated using Leucoverin and 5-flurouracil and lung cancer patients were treated using paclitaxel and carboplatin combination. Leucoverin is a class of folic acid analogue that works by protecting healthy cells from the effects methotrexate or similar medications while allowing their entering and killing cancer cells. Cisplatin is a platinum based chemotherapeutic agent used to treat cancer; it works by stopping the cancer cells from multiplying through binding of the cancer cell genetic material such as DNA, RNA.etc. Cisplatin based new generation cytotoxic gents for combined modality therapy offer better survival outcomes than those treated with carboplatin [21].However, several factors including age, co-existing conditions, stage at diagnosis, and performance status have strong associations with the choice of chemotherapeutic agents and which couldn't be studied in this population.

Analysis of the treatment chart indicated that the comorbidities were managed with routine drugs which are used to treat these conditions in patients without cancer. No specific drug was prescribed due to the presence of cancer, but this needs to be studied further with a much larger sample. Study results highlight the need for clinical awareness about comorbid illnesses. Furthermore, there is also urgent need for the development and evaluation of alternative effective but less toxic treatment regimens for better management of cancer as well as comorbidities [22]. In general, comorbid conditions must have more attention, especially during cancer management. Because, anticancer drugs may worsen the comorbidities or, at the least, may have adverse interaction with comorbid drugs.

Overall, this study recruits all type of cancer patients in a tertiary care hospital with a small sample size for each cancer, which may be the reason for insignificant results. In future, the impact of comorbidity has to studied in a single cancer type with large sample size as part of a multi centric study to acquire better results.

\section{CONCLUSION}

Comorbidities are associated with decreased overall estimated survival rates across most cancer types. However, the association was only clearly apparent in breast cancer. Many reports suggest that the estimated survival rate decreases as the age increases, which was not studied in this population.

The performance of cancer patients without comorbidities was higher, which means that comorbidities are an obstacle for the improvement of the health status in cancer patients. So, it is evident that the presence of comorbidities in cancer patients gives a negative outcome by reducing estimated survival rates and performance status. This study results show that in almost all cancer patients, the prognosis worsened with presence of comorbidities in terms of the CCI score, estimated survival rates, and performance scores. Prescribers have to be aware of comorbid conditions before they start the management of cancer, which may change definitive therapy regimen. Also, the drugs for the management of comorbidities could have related interaction problems with the prescribed antineoplastic agents.

Comorbid conditions have an adverse effect on patients diagnosed with cancer in terms of decreased estimated survival rates and performance scores. Therefore, comorbidity evaluation should be routinely added to the daily case sheet for the decision making process in patients with cancer in order to attain the aim of improving their treatment outcomes and quality of life. 
The limitations of the study are small sample size and single centre study. Also, it lacks correlation of data on covariates such as age, stage of cancer, drugs given for comorbid conditions, and response to therapy, which may influence estimated survival rates and treatment patterns. In future, this study could be extended to larger samples of different cancers with co-existing medical conditions. Nonetheless, our findings are consistent with previous studies, which have indicated higher mortality among cancer patients with comorbidity compared with those without comorbidity. Due to this reason, comorbid factors should be kept in attention while planning optimal therapy for individual cancer patients.

\section{MATERIALS AND METHODS}

\subsection{Study site and population}

A hospital based prospective - observational parallel group study was conducted at a 1000 bedded multi-specialty teaching hospital located in the southern region of Tamil Nadu, for a period of 10 months. All patients diagnosed with cancer were included in the study except ICU patients, pregnant women, nursing mothers, and patients who were not willing to participate. The protocol of the study was approved by the Institutional Human Ethics Committee of our hospital. Informed consent was obtained from all the participants prior to participating. A total of 140 cancer patients were recruited for the study with 70 patients in each arm i.e., 70 cancer patients without co-morbid conditions and 70 cancer patients with various comorbid conditions.

\subsection{Data collection}

Socio-demographic data such as age, sex, diet history, family history, past medical and medication history including comorbidities were collected. Apart from these, the laboratory investigation results, final diagnosis of the type of cancer, the existing comorbidities and their treatment pattern, monitoring parameters, and medications on discharge were also recorded.

\subsection{Study tools}

The severity of the comorbidity and the estimated survival rates were assessed using the Charlson Comorbidity Index [8] and the performance score of patients was marked using the Eastern Cooperative Oncology Group (ECOG) Performance status.

\subsubsection{Charlson Comorbidity Index (CCI)}

For patients with comorbid conditions, the severity of the comorbidity and the estimated survival rates were assessed using Charlson-comorbidity index. This index predicts the ten-year mortality for a patient who may have a range of comorbid conditions (a total of 19 conditions), each with assigned weight from 1- 6 according to risk of dying within one year. The Charlson score is summed up to provide a total score, which predicts the survival rate of each patient [23]. The difference in the performance of cancer patients with and without comorbidity was also studied.

\subsubsection{Eastern Cooperative Oncology Group (ECOG)}

The activities and performance of the patients were assessed using ECOG (Eastern Cooperative Oncology Group) scale [24]. The ECOG scale of performance status (PS) is widely used to quantify the functional status of cancer patients, and it determines prognosis in a number of malignant conditions. The PS describes the status of symptoms and functions with respect to ambulatory status and need for care. The description of PS includes 5 scores: PS 0 means normal activity, PS 1 means some symptoms, but still near fully ambulatory, PS 2 means less than $50 \%$ of daytime in bed, PS 3 means more than 50\% of daytime in bed, PS 4 means completely bedridden, and PS 5 means dead. The ECOG score was correlated with the duration of the patient estimated survival, the response to treatment, and also with their quality of life and co-morbidity. The treatment patterns of both cancer and comorbidities were subsequently noted and compared.

\subsection{Statistical analysis}

The different variables on which the patients were categorized were statistically analysed using SPSS Version 19. The chi-square test was used to determine whether there was a significant difference between mean and standard deviation of category variables between patients with and without comorbidity. $Z$ statistic was used for compare the two proportions between the groups. 
Acknowledgement: We would like to thank PSG College of Pharmacy, Department of Oncology - PSG Hospitals, Clinical sites, and the patients for their participation. We also thank Dr Sivaram Hariharan, for his extensive English proof reading and editing services.

Author contributions: Concept -V.S., R.P.; Design -V.S., R.P., SJ, V.I.; Supervision -V.S., R.P; Resource - R.P.,SM, SJ, VI; Materials - R.P., S.M.; Data Collection and/or Processing - R.P., SM., V.S.; Analysis and/or Interpretation - R.P., V.S.; Literature Search - R.P., SM.; Writing -R.P.; SP.; Critical Reviews -V.S.; R.P.;S.J.; V.I.;S.M.

Conflict of interest statement: The author reports no conflicts of interest. The author alone is responsible for the content and writing of the article.

\section{REFERENCES}

[1] Varghese C. 50 years of cancer control in India. In: Varghese C. (Eds). Cancer Prevention and Control in India, Government of India, New Delhi: MHFW 2002, pp. 48-59.

[2] Hall SF, Rochon PA, Paszat LF, Groome PA, RohlandSL. Measuring comorbidity in patients with head and neck cancer. Laryngoscope. 2002; 112(1):1988-1996. [CrossRef]

[3] Søgaard M, Thomsen RW, Bossen KS, Sørensen HT, Nørgaard M. The impact of comorbidity on cancer survival: a review. Clin Epidemiol.2013; 5(1): 3-29. [CrossRef]

[4] Fouad MN, Mayo CP, Funkhouser EM, Irene Hall H, Urban DA, Kiefe CI. Comorbidity independently predicted death in older prostate cancer patients, more of whom died with than from their disease. J Clin Epidemiol.2004; 57(7): 721-729. [CrossRef]

[5] Geraci JM, Escalante CP, Freeman JL, Goodwin JS. Comorbid disease and cancer: the need for more relevant conceptual models in health services research. J Clin Oncol.2005; 23(30): 7399-7404. [CrossRef]

[6] Mallath MK, Taylor DG, Badwe RA, Rath GK, Shanta V, Pramesh CS, Digumarti R, Sebastian P, Borthakur BB, Kalwar A, Kapoor S, Kumar S, Gill JL, Kuriakose MA, Malhotra H, Sharma SC, Shukla S, Viswanath L, Chacko RT, Pautu JL, Reddy KS, Sharma KS, Purushotham AD, Sullivan R. The growing burden of cancer in India: epidemiology and social context. Lancet Oncol.2014; 15(6):205-212. [CrossRef]

[7] Gopalakrishnan S, Umadevi R. An epidemiological analysis of cancer patients admitted to hospitals in Chennai, Tamil Nadu. Int J Community Med Public Health. 2015; 2(1):3-9. [CrossRef]

[8] Ershler WB, Longo DL. Aging and Cancer: Issues of Basic and Clinical Science. J Natl Cancer Inst. 1997; 89(20):1489 $-1497$.

[9] Land LH, Dalton SO, Jensen MB, Ewertz M. Influence of co morbidity on the effect of adjuvant treatment and age in patients with early-stage breast cancer. Br J Cancer.2012; 107(11): 1901-1907. [CrossRef]

[10] Ording G, Cronin-Fenton DP, Jacobsen JB, Nørgaard M, Thomsen RW, Christiansen P. Comorbidity and survival of Danish breast cancer patients from 2000-2011: a population-based cohort study. Clin Epidemiol. 2013(1); 5:39-46. [CrossRef]

[11] Sarfati D, Gurney J, Stanley J, Koea J. A retrospective cohort study of patients with stomach and liver cancers: the impact of comorbidity and ethnicity on cancer care and outcomes. BMC Cancer.2014; 14:821. [CrossRef]

[12] Deleuran T, Thomsen RW, Nørgaard M, Jacobsen JB, Rasmussen TR. Comorbidity and survival of Danish lung cancer patients from 2000-2011: a population-based cohort study. Clin Epidemiol.2013(1); 5:31-38. [CrossRef]

[13] Ostenfeld EB, Nørgaard M, Thomsen RW, Iversen LH, Jacobsen JB, Søgaand M. Comorbidity and survival of Danish patients with colon and rectal cancer from 2000-2011: a population-based cohort study. Clin Epidemiol.2013; 5(1):65-74. [CrossRef]

[14] Erichsen R, Horváth-Puh E, Iversen LH, Lash TL, Sørensen HT. Does comorbidity interact with colorectal cancer to increase mortality? A nationwide population-based cohort study. Br J Cancer.2013; 109(7):2005-2013. [CrossRef]

[15] Shinn EH, Lenihan DJ, Urbauer DL, Karen M. Engquist B, Valentine A, Palmero L, Woods ML, Pooja Patel P, Nick AM, Shahzad MK, Stone RL,Golden A, Atkinson E,Lutgendorf SK, Sood AK. Impact of cardiovascular comorbidity on ovarian cancer mortality. Cancer Epidemiol Biomarkers Prev.2013; 22(11): 2102-2109. [CrossRef]

[16] Ranc K, Jørgensen ME, Friis S, Carstensen B. Mortality after cancer among patients with diabetes mellitus: effect of diabetes duration and treatment. Diabetologia. 2014;57(5): 927-934. [CrossRef]

[17] Shieh SH, Probst JC, Sung FC, Tsai WC, Li YS, Chen CY. Decreased survival among lung cancer patients with comorbid tuberculosis and diabetes. BMC Cancer. 2012; 12: 174 -181. [CrossRef] 
[18] Li J, Cao G, Qingyong M, Liu H, Li W, Han L. The bi directional interaction between pancreatic cancer and diabetes.World J Surg Oncol.2012; 10:171-180. [CrossRef]

[19] Bellury L, Pett MA, Ellington L , Beck SL, Clark JC, Stein KD .The effect of aging and cancer on the symptom experience and physical function of elderly breast cancer survivors. Cancer. 2012; 118(24):6171-6178. [CrossRef]

[20] Demirpence M,Akman T, Oztop I, Unek IT, Yavuzsen T, Yilmaz AU. Impact of accompanying comorbidities on survival in patients with stage IIIB- IV non-small-cell lung cancer. Int J Hematol Oncol.2014; 24(4):223 - 232. [CrossRef]

[21] Ozkaya S, Findik S, Dirican A, Atici AG. Long-term survival rates of patients with stage IIIB and IV non-small cell lung cancer treated with cisplatin plus vinorelbine or gemcitabine. Exp Ther Med.2012; 4(6): 1035-1038. [CrossRef]

[22] Mohammadi M , Cao Y, Glimelius I, Bottai M, Eloranta S, Smedby KE. The impact of comorbid disease history on all-cause and cancer-specific mortality in myeloid leukemia and myeloma - a Swedish population-based study. BMC Cancer.2015; 15:850 - 861. [CrossRef]

[23] Charlson ME, Pompei P, Ales KL, MacKenzie CR. A new method of classifying prognostic comorbidity in longitudinal studies: development and validation. J Chronic Dis. 1987; 40(5): 373-383.

[24] Oken MM, Creech RH, Tormey DC, Horton J, Davis TE, McFadden ET. Toxicity and response criteria of the eastern cooperative oncology group. Am J Clin Oncol. 1982; 5(6):649-655.

This is an open access article which is publicly available on our journal's website under Institutional Repository at http://dspace.marmara.edu.tr. 